\title{
Apolipoprotein A-IV inhibits experimental colitis
}

\author{
Thorsten Vowinkel,1,2 Mikiji Mori," Christian F. Krieglstein,2 Janice Russell,, \\ Fumito Saijo, ${ }^{3}$ Sulaiman Bharwani, ${ }^{4}$ Richard H. Turnage, ${ }^{3}$ W. Sean Davidson, ${ }^{5}$ \\ Patrick Tso, ${ }^{5}$ D. Neil Granger, ${ }^{1}$ and Theodore J. Kalogeris ${ }^{1,3}$

\begin{abstract}
1Department of Molecular and Cellular Physiology, Louisiana State University Health Sciences Center, Shreveport, Louisiana, USA ${ }^{2}$ Department of General Surgery, Westfälische Wilhelms-Universität Münster, Munster, Germany. ${ }^{3}$ Department of Surgery and ${ }^{4}$ Department of Pediatrics, Louisiana State University Health Sciences Center, Shreveport, Louisiana, USA.

${ }^{5}$ Department of Pathology and Laboratory Medicine, College of Medicine, University of Cincinnati, Cincinnati, Ohio, USA.
\end{abstract}

\begin{abstract}
The antiatherogenic properties of apoA-IV suggest that this protein may act as an anti-inflammatory agent. We examined this possibility in a mouse model of acute colitis. Mice consumed $3 \%$ dextran sulfate sodium (DSS) in their drinking water for 7 days, with or without daily intraperitoneal injections of recombinant human apoA-IV. apoA-IV significantly and specifically delayed the onset, and reduced the severity and extent of, DSS-induced inflammation, as assessed by clinical disease activity score, macroscopic appearance and histology of the colon, and tissue myeloperoxidase activity. Intravital fluorescence microscopy of colonic microvasculature revealed that apoA-IV significantly inhibited DSS-induced leukocyte and platelet adhesive interactions. Furthermore, apoA-IV dramatically reduced the upregulation of P-selectin on colonic endothelium during DSS-colitis. apoA-IV knockout mice exhibited a significantly greater inflammatory response to DSS than did their WT littermates; this greater susceptibility to DSS-induced inflammation was reversed upon exogenous administration of apoA-IV to knockout mice. These results provide the first direct support for the hypothesis that apoA-IV is an endogenous anti-inflammatory protein. This anti-inflammatory effect likely involves the inhibition of P-selectin-mediated leukocyte and platelet adhesive interactions.
\end{abstract}

\section{Introduction}

apoA-IV was described over 25 years ago as a component of intestine-derived, triglyceride-rich lipoproteins (1). It is expressed in the small intestine, and its synthesis and secretion increase in response to a fatty meal (2-4). apoA-IV is secreted on lymph chylomicrons. During subsequent plasma passage and metabolism of chylomicrons, about $25 \%$ of apoA-IV is transferred to HDL. The remaining $75 \%$ is found in the lipoprotein-free fraction of plasma $(5,6)$. apoA-IV has several proposed roles, including lipid transport, lipoprotein metabolism (7-11), and control of food intake $(12,13)$ and gastric function (14). Most recently, apoA-IV has been shown to be antiatherogenic (15-18), and there is also evidence supporting apoA-IV antioxidant activity (18-20).

Two mechanisms have been suggested for apoA-IV's antiatherogenic action: enhancement of cellular lipid efflux (i.e., "reverse cholesterol transport") $(17,21)$ and antioxidant activity $(18-20)$. Another possible explanation is that apoA-IV is an anti-inflammatory protein. This is consistent with its antioxidant activity and is reasonable in view of (a) recognition that atherosclerosis is an inflammatory disorder of the vasculature (22), and (b) the widespread experimental efficacy of antioxidants in models of inflammatory disease (23). This hypothesis predicts that apoA-IV should be protective in other models of inflammation, but this possibility has not yet been examined. Similarly, while overexpression of apoA-IV in transgenic mice has been shown to protect against

Nonstandard abbreviations used: charge-coupled device (CCD); dextran sulfate sodium (DSS); disease activity index (DAI); inflammatory bowel disease (IBD); myeloperoxidase (MPO); recombinant human apoA-I (rhA-I); recombinant human apoA-IV (rhA-IV)

Conflict of interest: The authors have declared that no conflict of interest exists.

Citation for this article: J. Clin. Invest. 114:260-269 (2004)

doi:10.1172/JCI200421233. atherosclerosis (15-18), it is unknown whether apoA-IV deficiency promotes the opposite effect - greater susceptibility to disease.

The inflammatory bowel diseases (IBDs) are a set of disorders characterized clinically by severe diarrhea, weight loss, rectal bleeding, and abdominal pain. Affected regions of the colon and/or ileum show infiltration of leukocytes and lymphocytes, mucosal hyperplasia, interstitial edema, and mucosal ulcerations. Numerous experimental models for IBD have been described, with the most common models involving induction of the disease through the administration of toxic chemicals, such as acids, polysaccharides, or immune complexes (24-28). These agents reproduce many of the clinical, morphological, and pathophysiological symptoms of IBD.

Dextran sulfate sodium (DSS) is a heparin-like polysaccharide containing up to three sulfate groups per glucose molecule. Administered orally, it has been successfully used to induce both acute and chronic colitis in mice (24-28). DSS-induced colitis exhibits several characteristics resembling human ulcerative colitis, including weight loss, severe diarrhea and rectal bleeding, superficial ulceration, mucosal damage, production of cytokines, and leukocyte infiltration (24-28). This model has thus proved useful for examining fundamental mechanisms underlying the inflammatory pathophysiology associated with IBD, as well as screening potential therapeutic interventions.

In this study, we assessed the anti-inflammatory properties of apoA-IV in the DSS model of murine colitis by (a) examining the intensity of the inflammatory response and disease severity after exogenous administration of apoA-IV, and (b) testing whether endogenous apoA-IV has a protective role against DSS-induced disease in apoA-IV knockout mice. Our findings reveal a profound protective effect of apoA-IV and provide the first direct support for the hypothesis that apoA-IV is an endogenous antiinflammatory protein. 
A
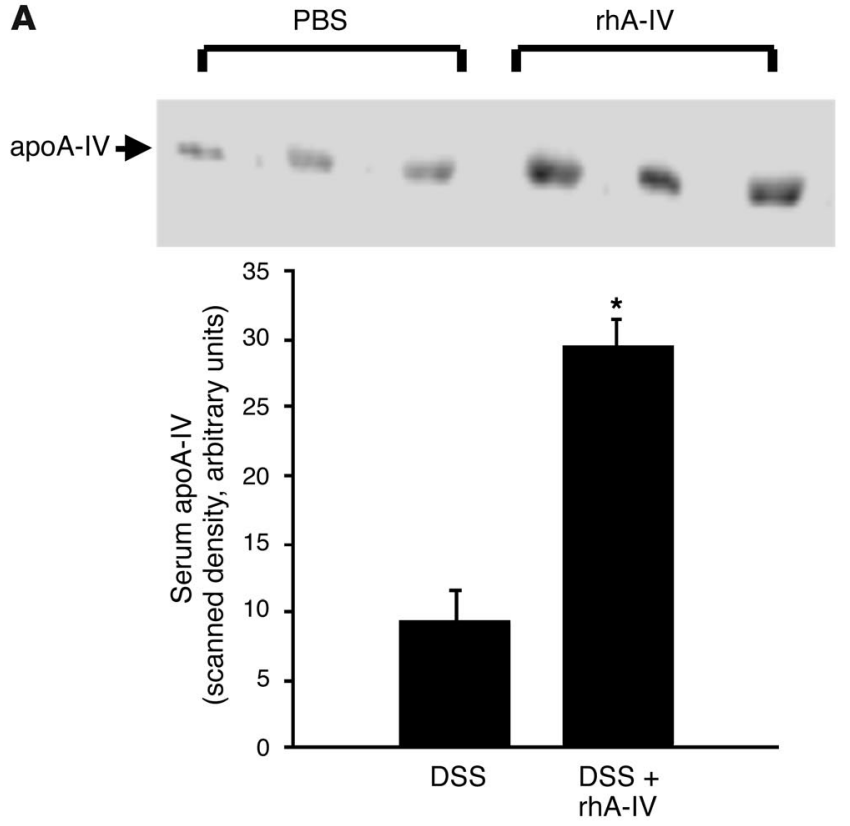

B

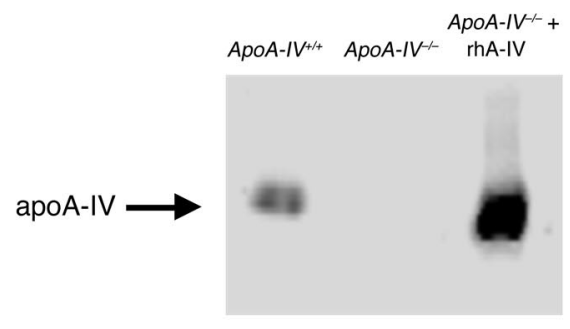

\section{Results}

Effect of exogenous administration of recombinant buman apoA-IV on serum apoA-IV. Western blot analysis performed at the conclusion of the 7-day experimental period showed a three- to fourfold elevation in serum apoA-IV in mice receiving recombinant human apoA-IV (rhA-IV) injections, compared with uninjected controls (Figure 1A).

Clinical indices of inflammation. All animals survived until sacrificed on day 6 (i.e., after 7 days of treatment). Each DSS-treated animal exceeded the previously established critical DSS load of $30 \mathrm{mg}$ DSS $/ \mathrm{g}$ body wt (29) without statistical difference between study groups (Figure 2). Control mice receiving water showed no clinical signs (diarrhea, fecal occult blood, perianal bleeding, rectal prolapse, weight loss) of spontaneous intestinal inflammation (Table 1 and Figure 3). Beginning on day 4, all mice treated with DSS showed significant differences in body weight compared with control mice; this was most prominent on day 6 (Table 1). Treatment with DSS produced experimental colitis as assessed by disease activity index (DAI, Figure 3 ) and by the shortened but heavier large bowel compared with control mice. No protective effect as measured by DAI was produced by PBS, BSA, or recombinant human apoA-I (rhA-I). Administration of rhA-IV $(0.5 \mathrm{mg} / \mathrm{d})$ significantly reduced the severity of DSS-induced colitis as assessed by colon weight-to-length ratio, body weight loss,

\section{Figure 2}

DSS load for all DSS-treated mice in each experimental series was calculated as described in Methods. In each group the critical DSS load of $30 \mathrm{mg}$ DSS per g body wt (dotted line) was met without statistical difference between study groups. NS, not significant.

\section{Figure 1}

Western blot analysis of circulating apoA-IV. Serum samples were obtained at the conclusion of the 7-day experimental period, about 24 hours after the last intraperitoneal injection of rhA-IV. Serum samples were subjected to SDS-PAGE on $10 \%$ gels, transferred to nitrocellulose, then probed using an affinity-purified rabbit anti-rhA-IV antibody, followed by HRP-coupled goat anti-rabbit IgG antibody. (A) Effect of rhA-IV injection on serum apoA-IV in C57BL/6 mice from series I experiments. (B) Serum apoA-IV in an ApoA-IV-/- mouse with or without exogenous administration of rhA-IV, compared with serum apoA-IV in a WT littermate.

and DAI as compared with the disease-active groups (DSS, DSS + PBS, DSS + BSA, and DSS + rhA-I). The lower dose of rhA-IV $(0.25 \mathrm{mg} / \mathrm{d})$ also produced significant reduction of all clinical and macroscopic inflammatory indices except for colon length.

Histology. Blinded histological injury scoring was quantified in the distal colon after 7 days of treatment. Control animals showed no signs of inflammation (see Figure 5A). In contrast, in mice receiving DSS, DSS + PBS, DSS + BSA, or DSS + rhA-I, the severity of colitis assessed by overall score as well as specific parameters (inflammation, extent, and crypt damage; see Methods for parameter values and scores) was significantly higher than that in controls (Figure 4). Inflammation was mainly confined to the mucosa with loss of goblet cells, crypt damage, mucosal ulceration, and accompanying submucosal edema (Figure 5B). Treatment of DSSfed animals with rhA-IV $(0.5 \mathrm{mg} / \mathrm{d})$ produced significant reduction of experimental colitis (Figure 5C) with a reduced total score and its specific parameters compared with DSS alone, DSS + PBS, DSS + BSA, and DSS + rhA-I. DSS + rhA-IV at $0.25 \mathrm{mg} / \mathrm{d}$ reduced the inflammatory score only as compared with the DSS + BSA group. The lower dose of rhA-IV allowed inflammatory cells to infiltrate submucosally (Figure 5D). These observations correlate well with the clinical and macroscopic findings (Table 1, Figure 3); moreover, they showed a tendency toward rhA-IV dose-dependent protection (though this did not reach statistical significance).

Lamina propria leukocytes. Quantitation of lamina propria leukocytes further confirmed rhA-IV's inhibitory effect on DSSinduced leukocyte recruitment. Examination of histological

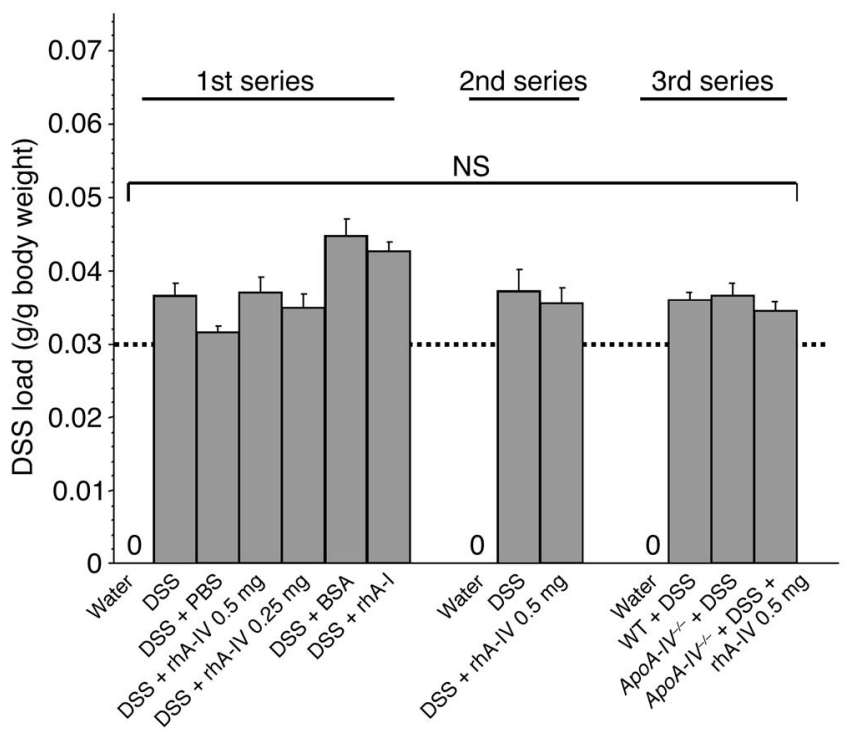


Table 1

Clinical indices of inflammation

\begin{tabular}{|c|c|c|c|}
\hline & $\begin{array}{l}\text { Body weight } \\
\text { change at } \\
\text { day } 6(\%)\end{array}$ & $\begin{array}{l}\text { Colon length } \\
\text { (cm) }\end{array}$ & $\begin{array}{c}\text { Colon } \\
\text { weight/length } \\
(\mathrm{mg} / \mathrm{cm})\end{array}$ \\
\hline Water & $102.1 \pm 2.0$ & $6.8 \pm 0.2$ & $30.2 \pm 2.5$ \\
\hline DSS & $81.8 \pm 2.6^{A}$ & $4.7 \pm 0.5^{A}$ & $46 \pm 3.1^{A}$ \\
\hline DSS + PBS & $87.2 \pm 1.3^{A}$ & $5.0 \pm 0.2^{A}$ & $42.1 \pm 6.8^{A}$ \\
\hline $\begin{array}{l}\text { DSS + } \\
\quad \text { rhA-IV } 0.5 \mathrm{mg}\end{array}$ & $99.1 \pm 2.6^{B, C, D, E}$ & $5.8 \pm 0.4^{A, B, D, E}$ & $29.6 \pm 3.1^{B, C, D, E}$ \\
\hline $\begin{array}{l}\text { DSS + } \\
\quad \text { rhA-IV } 0.25 \mathrm{mg}\end{array}$ & $100.3 \pm 2.8^{B, C, D, E}$ & $5.5 \pm 0.5^{\mathrm{A}}$ & $30.6 \pm 4.4 \mathrm{~B}, \mathrm{C}, \mathrm{D}, \mathrm{E}$ \\
\hline $\mathrm{DSS}+\mathrm{BSA}$ & $84.5 \pm 4.0^{\mathrm{A}}$ & $4.7 \pm 0.5^{A}$ & $42.8 \pm 0.3^{A}$ \\
\hline DSS + rhA-I & $87.8 \pm 3.6^{A, B}$ & $4.7 \pm 0.4^{A}$ & $50.2 \pm 5.2^{\mathrm{A}}$ \\
\hline
\end{tabular}

Percent indicates body weight change at day 6 compared with day $0 .{ }^{A} P<0.05$ vs. water, ${ }^{B} P<0.05$ vs. DSS, ${ }^{C} P<0.05$ vs. DSS + PBS, DP $<0.05$ vs. DSS + BSA, EP $<0.05$ vs. DSS + rhA-I. Data are mean \pm SE.

sections revealed $0 \pm 0$ neutrophils in lamina propria of control mice, $7.0 \pm 2.2$ neutrophils in DSS-treated mice, and $0 \pm 0$ neutrophils in mice cotreated with DSS and rhA-IV.

Tissue myeloperoxidase activity. Treatment with DSS, DSS + PBS, DSS + BSA, and DSS + rhA-I all produced significant increases in myeloperoxidase (MPO) activity compared with controls receiving water alone (Figure 6). MPO activity correlated closely with clinical, macroscopic, and histological grading of inflammation in the experimental groups. DSS-induced colonic MPO activity was decreased by at least $90 \%$ in response to rhA-IV at $0.5 \mathrm{mg} / \mathrm{d}$, compared with DSS, DSS + PBS, DSS + BSA, and DSS + rhA-I. The lower dose of rhA-IV $(0.25 \mathrm{mg} / \mathrm{d})$ also produced significant attenuation (by at least 50\%) of MPO activity compared with DSS + BSA treatment. These results strongly suggest inhibition of leukocyte recruitment as a potential mechanism for the protective effects of rhA-IV. There was a strong, though not statistically significant, tendency toward rhA-IV dose-dependent inhibition of leukocyte recruitment.

Intravital microscopy experiments. Daily administration of rhA-IV in DSS-treated animals significantly reduced the number of adherent platelets and leukocytes in postcapillary venules (Figure 7, A and B). Compared with venules of control mice, venules of DSS-colitic mice exhibited profound increases in the numbers of adherent platelets and leukocytes. A minority (2.4\%) of platelets was bound only to the endothelium; the majority (97.6\%) was adherent to the endothelium via leukocytes (Figure 7A). With regard to leukocyte adhesion, $42.5 \%$ of adherent leukocytes were platelet-free, and $57.5 \%$ were platelet-bearing (Figure 7B). Treatment of DSS-colitic mice with rhA-IV significantly reduced the number of adherent platelets by decreasing platelet-leukocyte binding to the endothelium (Figure 7A). Adhesion of both platelet-free leukocytes and platelet-bearing leukocytes was significantly reduced in rhA-IV-treated mice.

$P$-selectin expression. Significant accumulation of ${ }^{125} \mathrm{I} \mathrm{mAb}$ RB40.34 (anti-P-selectin $\mathrm{mAb}$ ) was observed in the entire colon of DSStreated mice, both in its proximal and distal portions, compared with control mice (Figure 8). Administration of rhA-IV produced a significant reduction of DSS-induced P-selectin expression, suggesting modulation of P-selectin expression as a mechanism whereby rhA-IV exerts its protection against intestinal inflammation.
Effect of DSS in ApoA-IV $V^{-/-}$mice. In the third series of experiments, we first examined the effect of DSS on ApoA-IV $V^{-/-}$mice in comparison with their WT littermates, to determine whether they had greater sensitivity to DSS-induced inflammation, and if so, to then determine whether such hypersensitivity could be reversed by exogenous rhA-IV. In contrast to their WT littermates, the ApoA-IV-/mice showed a complete absence of circulating apoA-IV; this was remedied by exogenous administration of rhA-IV (Figure 1B).

Control mice showed no signs of inflammation (see Figure 11A). WT littermates treated with DSS showed increased DAI, loss of body weight, increased colon weight-to-length ratio, and a significantly shortened colon compared with controls (Table 2 and Figure 9). The WT mice also had higher histology scores than control animals had (Figure 10), although this was not statistically significant, and H\&E staining showed only mild inflammation (Figure 11B).

Clinical and histological findings as well as MPO activity showed significantly more severe inflammation in DSS-treated knockout mice than in DSS-treated WT littermates (Table 2, Figures 9-12).

Daily administration of rhA-IV significantly attenuated all measures of DSS-induced disease in ApoA-IV $V^{-/}$animals (Table 2, Figures 9-12).

\section{Discussion}

Our objective was to examine the hypothesis that apoA-IV is antiinflammatory, using the DSS-colitic mouse, a well-established model of acute colonic inflammation (24-28). We sought answers to the following specific questions: (a) What is the effect of exogenous administration of apoA-IV on DSS-induced inflammation? (b) What is the effect of exogenously administered apoA-IV on DSSinduced platelet and leukocyte adhesive interactions in the colonic microvasculature? (c) Are animals lacking apoA-IV more sensitive to DSS-induced inflammation and injury, and if so, (d) can such sensitivity be reversed by exogenous administration of apoA-IV?

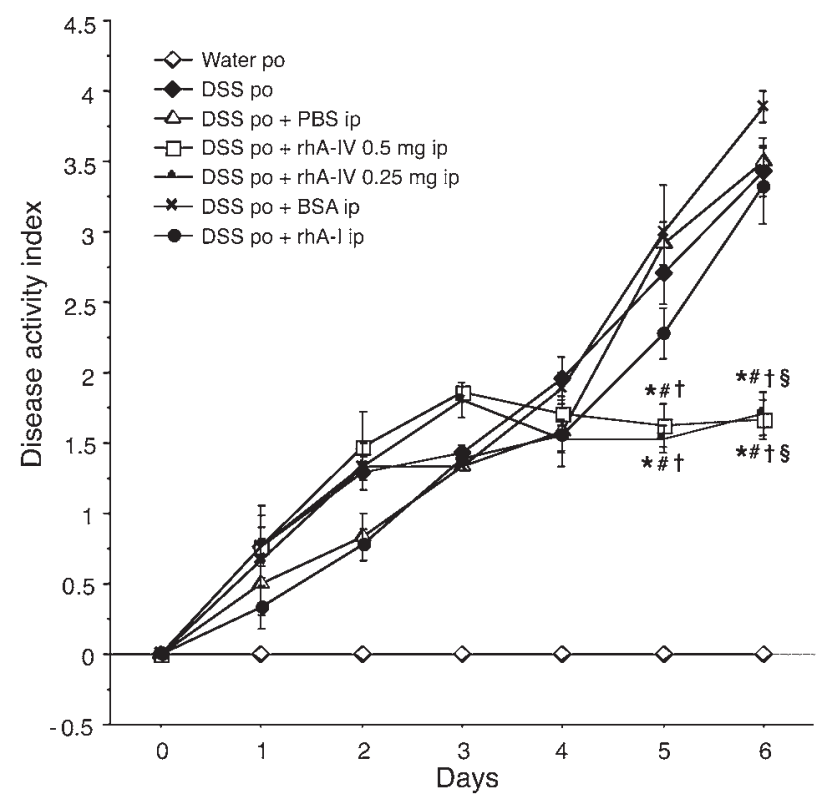

Figure 3

Changes in DAI over 7 days of treatment with water (control), DSS, DSS + PBS, DSS + $0.5 \mathrm{mg}$ or $0.25 \mathrm{mg}$ rhA-IV, DSS + BSA, or DSS + rhA-I (mean \pm SE). ${ }^{*} P<0.05$ vs. DSS, ${ }^{\#} P<0.05$ vs. DSS + PBS, ${ }^{\dagger} P<0.05$ vs. DSS + BSA, ${ }^{\S} P<0.05$ vs. DSS + rhA-I. ip, intraperitoneal; po, per os. 


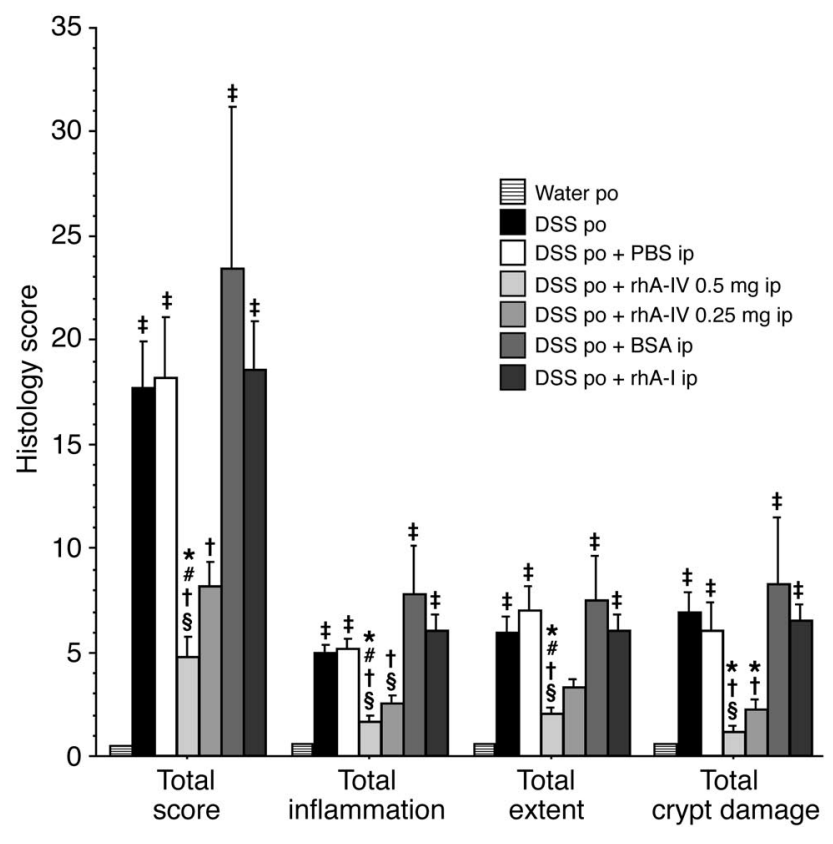

Figure 4

Blinded histological assessment of colitis in mice given water (control), DSS, DSS + PBS, DSS + BSA, DSS + rhA-I, or DSS + rhA-IV $(0.5 \mathrm{mg}$ or $0.25 \mathrm{mg})$. Total histological score was derived from the severity and extent of total inflammation and crypt damage. Three sections per mouse were analyzed (mean $\pm \mathrm{SE}$ ). ${ }^{\ddagger} P<0.05$ vs. water, ${ }^{*} P<0.05$ vs. DSS, ${ }^{*} P<0.05$ vs. DSS + PBS, ${ }^{\dagger} P<0.05$ vs. DSS + BSA, $\S P<0.05$ vs. DSS + rhA-I.

Our results reveal, we believe for the first time, a profound and specific anti-inflammatory action of exogenous apoA-IV in the DSS-colitic mouse, associated with a modulatory effect on leukocyte and platelet adhesive interactions and an inhibitory action on endothelial cell P-selectin expression in the colonic microvasculature. We also demonstrate a novel role for endogenous apoA-IV as an anti-inflammatory protein.

Although it has been proposed (18-20) that apoA-IV-associated antioxidant activity could underlie its antiatherogenic effects (15-18), how such activity might be linked to apoA-IV-mediated protection has not previously been addressed. One possibility would be if apoA-IV's antiatherogenic action constituted one instance of a general anti-inflammatory role for this protein. The relationship between oxidant stress and inflammatory processes (e.g., microvascular recruitment of leukocytes) is well-established (23), and may be a mechanistic link between apoA-IV's antioxidant activity and its ability to protect. With regard to apoA-IV, this is a novel hypothesis; if true, it predicts that apoA-IV should be protective in other experimental models of inflammation. These considerations provided the rationale for the present study.

DSS-induced colitis is a commonly used model for the inflammatory component of IBD. Induction of disease is rapid, and clinical and histological measures of disease activity closely resemble those seen in human ulcerative colitis. Although the pathogenesis of DSS-mediated colitis is incompletely understood, DSS is thought to induce mucosal injury and inflammation initially through a direct toxic effect on epithelial cells, with subsequent recruitment and activation of inflammatory cells and upregulation of inflammatory mediators, leading to the development of severe colitis (30).
Recently, the particular roles of oxidant stress (31) and leukocyte adhesion (32) in DSS-colitis were demonstrated. In our study, all indices of DSS-induced inflammatory disease were significantly ameliorated by treatment with apoA-IV but not apoA-I; apoA-IV knockout mice were more susceptible to the colitis-inducing effects of DSS; and the greater sensitivity of the knockout mice to DSS was reversed upon exogenous administration of apoA-IV. Finally, apoA-IV reversed DSS-induced leukocyte recruitment and P-selectin expression in the colonic microvasculature. These results demonstrate that apoA-IV exerts an anti-inflammatory action in the DSS-colitic mouse.

Previously we reported a correlation between the ingested DSS load and the severity of colonic inflammation in DSS-induced colitis (29). A critical DSS load exceeding $30 \mathrm{mg} / \mathrm{g}$ body wt is required to achieve comparable severity of inflammation. Once this critical load is met, further increases in DSS-supplemented fluid intake do not alter the severity of the inflammatory response. Monitoring DSS load is particularly crucial when the investigated agent potentially alters food and/or water consumption (33-35). Since an inhibitory effect of apoA-IV on feeding behavior has been reported $(12,13)$, it was important to rule out the possibility that any protective effect of apoA-IV was not secondary to an effect on water ingestion (i.e., limiting ingested DSS load to a non-injury-producing dose). Any animal that did not meet the aforementioned minimum load criterion was discarded from the analysis. Each group reported here consistently showed DSS loads exceeding $30 \mathrm{mg} / \mathrm{g}$ body wt, and thus our results reflect apoA-IV-mediated protection that is independent of ingested DSS load.

apoA-IV significantly reduced the severity of DSS-induced colonic injury as assessed by DAI. By the end of the 7-day experimental period, body weights in the two apoA-IV-treated groups ( 0.25 and $0.5 \mathrm{mg} / \mathrm{d}$ ) were not significantly different from the control group
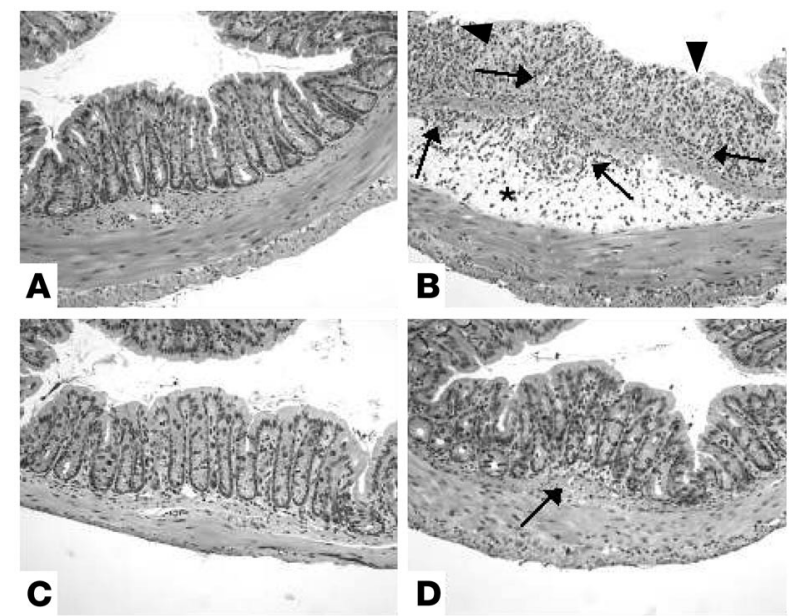

\section{Figure 5}

Histology (H\&E staining; magnification, $\times 100$ ) of colonic samples taken from mice receiving either water (control), DSS, DSS + $0.5 \mathrm{mg}$ rhA-IV, or DSS $+0.25 \mathrm{mg}$ rhA-IV. Compared with that of control animals (A), colon of DSS-treated mice (B) shows complete destruction of epithelial architecture (arrowheads), with nearly complete loss of crypts, loss of epithelial integrity, edema (asterisk), and intense cellular inflammation in all layers (arrows). Treatment with $0.25 \mathrm{mg}$ rhA-IV attenuated morphological damage but showed mild cellular infiltrate (D, arrow), whereas epithelial architecture was preserved in animals receiving the higher dose of $0.5 \mathrm{mg}$ rhA-IV (C). 


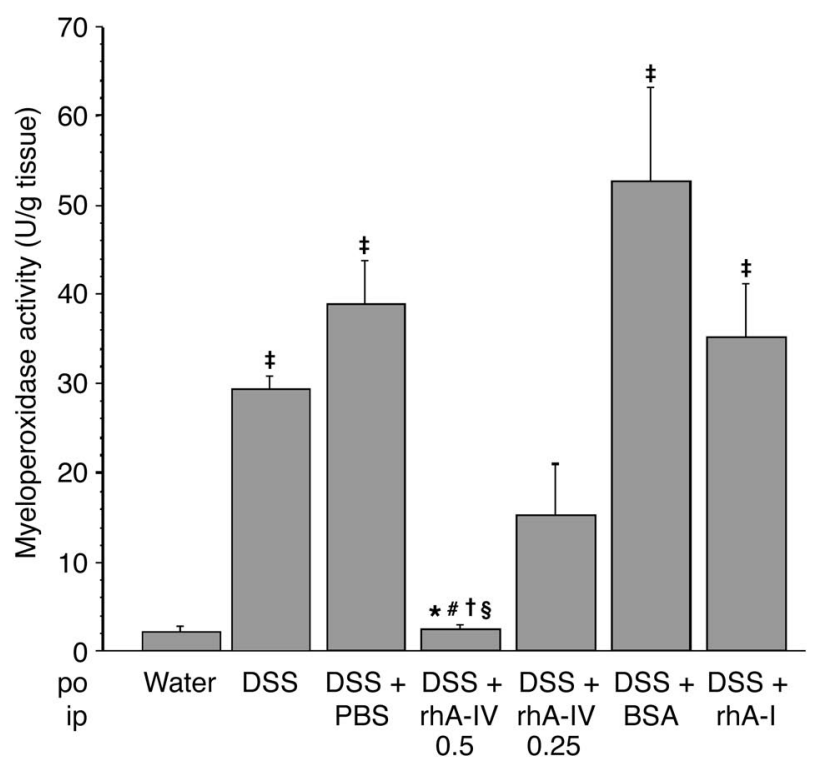

Figure 6

MPO activity in colonic tissue of water-treated control mice, animals receiving DSS, DSS + PBS, DSS + rhA-IV $(0.5 \mathrm{mg}$ or $0.25 \mathrm{mg})$, DSS + BSA, or DSS + rhA-I, after 7 days. Tissue MPO was measured as described in Methods (mean \pm SE). ${ }^{\ddagger} P<0.05$ vs. water, ${ }^{*} P<0.05$ vs. DSS, ${ }^{\#} P<0.05$ vs. DSS + PBS, ${ }^{\dagger} P<0.05$ vs. DSS + BSA, ${ }^{\S} P<0.05$ vs. DSS + rhA-I.

receiving water alone, and the DAI in the mice treated with DSS + rhA-IV was half that of those receiving DSS alone. This effect was apoA-IV-specific, since administration of neither BSA nor rhA-I at equimolar doses conferred protection.

Two more-specific indices of inflammation, colon weight-tolength ratio and tissue histology, both confirmed the significant and specific protective effect of apoA-IV. The latter showed a trend toward an apoA-IV dose response in all histological indices of inflammation. This protective trend was also evident in measurements of MPO activity in colonic tissue, and at $0.5 \mathrm{mg} / \mathrm{d}$, apoA-IV completely prevented a DSS-induced increase in colonic MPO activity, demonstrating apoA-IV-mediated interference with the recruitment of leukocytes to the site of inflammation. Our intravital studies provide separate, direct confirmation of an inhibitory effect of apoA-IV treatment on neutrophil adhesion to colonic endothelium and on platelet adhesive interactions. The dual radiolabeled antibody experiments suggest that apoA-IV's protective effects are exerted by inhibiting P-selectin expression.

It has been demonstrated that neutrophil accumulation plays an important role in DSS-induced colitis, since the disease can be attenuated when anti-neutrophil serum is administered (36). Tissue accumulation of circulating leukocytes is mediated by a coordinated expression of specific adhesion molecules on the surface of endothelial cells and leukocytes, regulating the interactions between these cells in the microcirculation and allowing leukocytes to roll, firmly adhere, and emigrate $(37,38)$. P-selectin appears to be a particularly critical adhesion molecule that is dramatically upregulated in the inflamed tissue of patients with IBD (39). In animal studies of experimental colitis, blockage of P-selectin significantly decreases leukocyte rolling and adhesion in colonic venules and attenuates disease activity $(32,40)$. Here, we report that apoA-IV inhibits leukocyte recruitment into the inflamed tissue and correspondingly inhibits P-selectin expression, suggesting that the attenuating effect of apoA-IV on leukocyte recruitment results from an action of the lipoprotein on endothelial cell P-selectin expression.

There are several lines of evidence supporting an intimate connection between the hemostatic and inflammatory system (i.e., between platelets and leukocytes) and a role for platelets in modulating acute and chronic inflammatory responses. Intravascular platelet aggregates have been identified in mucosal biopsies of patients with ulcerative colitis, and there is an increase in circulating platelet aggregates in the mesenteric venous circulation draining the inflamed bowel in ulcerative colitis (41). These findings are consistent with (a) elevated platelet counts in human IBD, (b) use of thrombocytosis as a marker of disease activity, and (c) occurrence of mucosal microinfarctions and an increased risk of systemic thromboembolism in patients with IBD (42-44). Platelets are recognized as active contributors to human mucosal inflammation and IBD pathogenesis (45). However, there has been little experimental work in animal models addressing the role of platelets in intestinal inflammation. Similarly, little is known of platelet-leukocyte interactions in IBD. Here, we used intravital fluorescence microscopy to simultaneously visualize platelets and leukocytes in experimental colitis. In DSS-treated animals, platelet adhesion was mainly mediated by leukocytes,

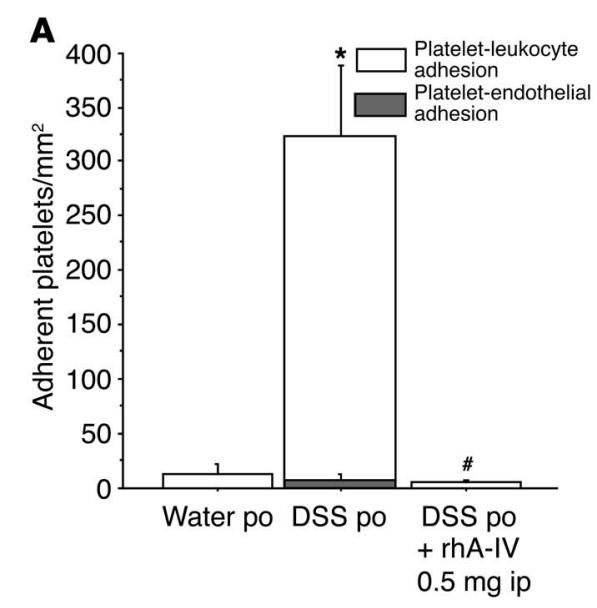

Figure 7

Total adhesion of platelets (A) and leukocytes (B) in postcapillary colonic venules after 7 days of water (control), DSS, or DSS + $0.5 \mathrm{mg}$ rhA-IV. Mice were infused with fluorescently labeled WT (C57BL/6J) platelets and rhodamine $6 \mathrm{G}$ to simultaneously visualize leukocytes. (A) Gray bars: number of platelets/ $\mathrm{mm}^{2}$ adhering directly to the vessel wall. White bars: number of platelets adhering to leukocytes $/ \mathrm{mm}^{2}$. (B) Gray bars: number of platelet-free leukocytes $/ \mathrm{mm}^{2}$. White bars: number of platelet-bearing leukocytes $/ \mathrm{mm}^{2} .{ }^{*} P<0.05$ relative to control, ${ }^{\# \dagger} P<0.05$ relative to DSS. 


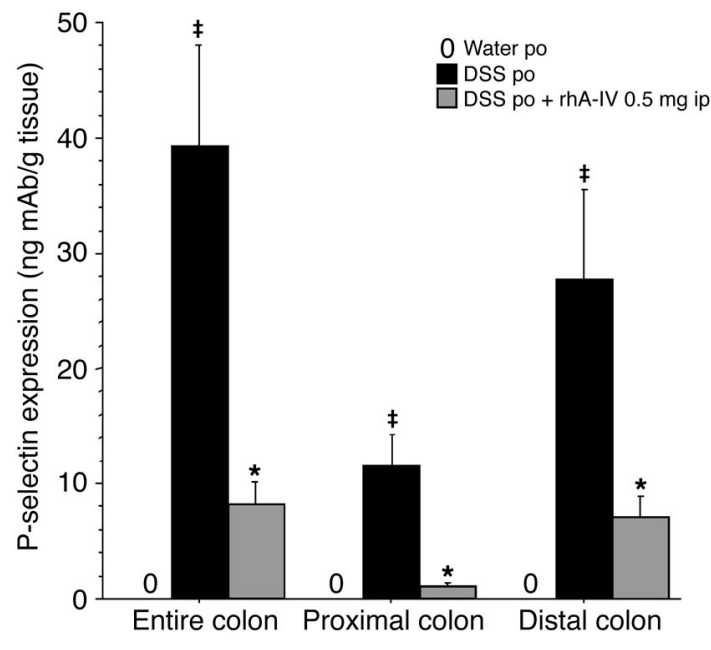

Figure 8

Changes in endothelial P-selectin expression in the proximal and distal colon and as a sum in the entire colon of control mice (water po), DSS-treated mice, and DSS-treated mice also receiving rhA-IV (mean $\pm \mathrm{SE}) .{ }^{\ddagger} P<0.05$ vs. water, ${ }^{\star} P<0.05$ vs. DSS.

since the majority of platelet adhesion was seen in the context of platelet-leukocyte aggregates. Treatment of DSS-colitic mice with apoA-IV resulted in significant inhibition of platelet-leukocyte aggregate formation in addition to decreasing the adhesion of platelet-free and platelet-bearing leukocytes to the endothelium. These findings indicate that apoA-IV modulates both the recruitment of leukocytes and the crosstalk between platelets and leukocytes - again, possibly by inhibiting P-selectin expression.

Previous studies in other models have demonstrated anti-inflammatory effects of HDL or reconstituted HDL particles containing apoA-I (46-48). Although apoA-IV can associate with HDL, a specific anti-inflammatory role for HDL-associated apoA-IV has never been examined. Most apoA-IV is present in the lipoprotein-free fraction of plasma $(5,6)$, and the physiological role of this pool of apoA-IV has never been investigated. Since apoA-I is the major apolipoprotein of the HDL complex, the protective effects of HDL have been ascribed to apoA-I (46-48). Our finding of a protective effect of apoA-IV, but not purified apoA-I, is not specific to the DSS-colitis model, since purified, free apoA-I is also ineffective in blocking oxidant-induced barrier dysfunction in endothelial cells (49) and redox-dependent apoptosis in PC12 cells (50). Thus, it is possible that in order to be protective, apoA-I protein must be delivered on an HDL or HDL-like particle. If this is true, our results demonstrate that apoA-IV-mediated protection does not have a similar requirement.

Although previous transgenic studies have clearly demonstrated the antiatherogenic effect of overexpression of apoA-IV (15-18), the potential protective role of endogenous apoA-IV has not been previously examined. The single previous apoA-IV knockout study (51) examined factors relevant to lipid absorption, plasma lipid/ lipoprotein metabolism, and feeding behavior, but did not explore a possible protective effect of apoA-IV on atherosclerosis or other inflammatory disease. In an attempt to evaluate the physiological importance of apoA-IV as an anti-inflammatory protein, we examined the response of ApoA-IV $V^{-/-}$mice to DSS. We found that compared with their WT littermates, knockout animals were signifi- cantly more sensitive to the inflammatory effects of DSS. To test the specificity of the knockout effect, we then examined whether the ApoA-IV $V^{-/-}$mice could be "rescued" by exogenous administration of apoA-IV. Since exogenous apoA-IV had a protective effect on knockout animals, our results clearly demonstrate that greater sensitivity of $A p o A-I V^{-/-}$mice to DSS-induced colonic inflammation is due to specific deficiency of apoA-IV.

In summary, the present studies, conducted in a murine model of DSS-colitis, provide the first direct evidence in support of a novel action for apoA-IV as an anti-inflammatory protein. This action may be explained by an inhibitory effect of apoA-IV on P-selectin expression that modulates leukocyte and platelet adhesive interactions. We further show that this anti-inflammatory activity may be a novel physiological role for endogenous apoA-IV. We propose that apoA-IV's previously documented antiatherogenic effects may represent a particular case of apoA-IV-mediated anti-inflammatory activity. The precise relationship between apoA-IV's presumed antioxidant activity and the protective effects reported here is not yet defined; however, preliminary cell culture studies in our laboratory support a direct modulatory effect of apoA-IV upon oxidant-induced, intracellular redox-dependent cell signaling mechanisms (50). The hypothesis that apoA-IV's anti-inflammatory effects in vivo in addition to inhibition of P-selectin expression could also be mediated through such a mechanism is the subject of ongoing investigation in our laboratory.

\section{Methods}

Animals. Male C57BL/6J mice were purchased from The Jackson Laboratory (Bar Harbor, Maine, USA). Male ApoA-IV-/- (51) animals were originally obtained from J.L. Breslow and were backcrossed onto the parent $\mathrm{C} 57 \mathrm{BL} / 6 \mathrm{~J}$ strain for eight generations. Animals were maintained on a 12-hour light/12-hour dark cycle under pathogen-free conditions. The mice had ad libitum access to a standard diet and water until reaching the desired age (8-10 weeks) and/or weight (20-25 g). All procedures using animals were reviewed and approved by the Institutional Animal Care and Use Committee of Louisiana State University Health Sciences Center and were performed according to the criteria outlined by the NIH.

Recombinant human apoA-IV. We produced rhA-IV using the apoA-IV expression vector $\mathrm{pL} 2102-\mathrm{hA}-\mathrm{IV}$, modified from $\mathrm{pL} 1867-$ hA-IV, which was previously described by Duverger et al. (52). This construct encodes the full-length protein-coding portion of the apoA-IV gene, with a $6 \mathrm{X}$-histidine tag to facilitate purification. rhA-IV from this construct was previously demonstrat-

\section{Table 2}

Clinical indices of inflammation in $A p o A-I V^{--}$animals treated with DSS and rhA-IV

\begin{tabular}{lccc}
\hline & $\begin{array}{c}\text { Body weight } \\
\text { change at } \\
\text { day } \mathbf{6}(\%)\end{array}$ & $\begin{array}{c}\text { Colon length } \\
\mathbf{( c m )}\end{array}$ & $\begin{array}{c}\text { Colon } \\
\text { weight/length } \\
(\mathbf{m g} / \mathbf{c m})\end{array}$ \\
WT + water & $102.1 \pm 2.1$ & $6.8 \pm 0.5$ & $36.1 \pm 1$ \\
WT + DSS & $96.5 \pm 4.7$ & $5.3 \pm 0.5^{\mathrm{A}}$ & $41 \pm 3.8$ \\
ApoA-IV-- + DSS & $89.1 \pm 3.6^{\mathrm{A}, \mathrm{B}}$ & $4.8 \pm 0.2^{\mathrm{A}}$ & $43.9 \pm 2^{\mathrm{A}}$ \\
ApoA-IV-- + DSS + rhA-IV & $99 \pm 3.2^{\mathrm{C}}$ & $5.9 \pm 0.4^{\mathrm{A}, \mathrm{C}}$ & $34.5 \pm 3.9^{\mathrm{B}, \mathrm{C}}$
\end{tabular}

Percent indicates body weight change at day 6 compared with day 0 . ${ }^{A} P<0.05$ vs. WT treated with water; ${ }^{B} P<0.05$ vs. WT treated with DSS; ${ }^{c} P<0.05$ vs. ApoA- $/ V^{-1-}$ treated with DSS. Data are mean \pm SE. 


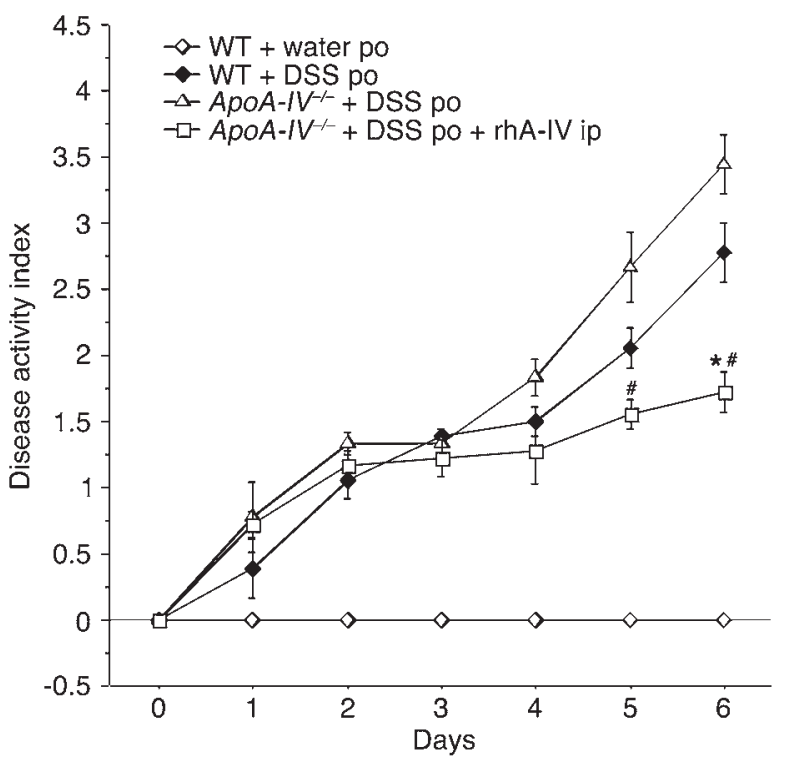

Figure 9

Changes in DAI over 7 days of treatment: WT mice treated with water (control) or DSS; ApoA-IV-I- mice treated with DSS alone or DSS + rhA-IV (mean \pm SE). ${ }^{*} P<0.05$ vs. WT treated with DSS, $\# P<0.05$ vs. ApoA-IV $V^{-1-}$ treated with DSS alone.

ed to be physicochemically and functionally similar to native human apoA-IV purified from plasma (52). rhA-IV was produced in BL21(DE3)pLysS competent cells (Promega Corp., Madison, Wisconsin, USA) after transformation with pL2102-hA-IV. After overnight culture, cells were diluted 1:4 with fresh media and allowed to grow to an $\mathrm{OD}_{610}$ of 0.5 , then induced for 2 hours with $1 \mathrm{mM}$ isopropyl $\beta$-D-thiogalactoside. Cells were harvested and washed, then lysed in $20 \mathrm{mM}$ PBS $\left(19.7 \mathrm{mM} \mathrm{NaH}_{2} \mathrm{PO}_{4}, 0.26 \mathrm{mM}\right.$ $\mathrm{Na}_{2} \mathrm{HPO}_{4}$, and $500 \mathrm{mM} \mathrm{NaCl}, \mathrm{pH}$ 7.8) by freeze-thawing followed by sonication. Bacterial lysates were incubated in batchwise fashion with $\mathrm{Ni}^{2+}$-charged agarose resin (Pro-Bond; Invitrogen Corp., Carlsbad, California, USA), then poured into an $18 \mathrm{~cm} \times 2 \mathrm{~cm}$ column. The column was washed extensively with $20 \mathrm{mM}$ PBS, followed by $20 \mathrm{mM}$ PBS plus $40 \mathrm{mM}$ imidazole; completeness of washing was monitored by continuous measurement of $\mathrm{OD}_{280}$ and by SDS-PAGE on selected fractions. rhA-IV was eluted from the column free of contaminating bacterial proteins using $20 \mathrm{mM}$ PBS plus $150 \mathrm{mM}$ imidazole. Eluted rhA-IV was dialyzed exhaustively against PBS ( $\mathrm{pH} 7.4$ ), concentrated against PEG 8000, filter-sterilized, and then stored in small aliquots at $-80^{\circ} \mathrm{C}$ until needed. Freshly thawed rhA-IV was used for all experiments.

rhA-I. rhA-I was produced as previously described (53), lyophilized, and dissolved in PBS injection vehicle immediately prior to administration. The injected molar dose of rhA-I ( 0.31 $\mathrm{mg} / \mathrm{d}$ ) was equivalent to $\mathrm{rhA}-\mathrm{IV}$ at $0.5 \mathrm{mg} / \mathrm{d}$.

Induction of colitis. Mice were administered 3\% DSS (mol wt, 40 kDa; ICN Biomedicals, Aurora, Ohio, USA) dissolved in water that was filter-purified (Millipore Corp., Bedford, Massachusetts, USA) for 7 days (day 0-6 ad libitum) (26). Control C57BL/6J mice received the filtered water alone.

Assessment of inflammation in DSS-treated mice. Clinical assessment of mice included daily measurement of body weight, evaluation of stool consistency, and the presence of blood in the stools by a guaiac paper test (ColoScreen; Helena Laboratories Inc., Beaumont, Texas, USA) (54). Clinical DAI (25) ranging from 0 to 4 was calculated using the following parameters: stool consistency (normal, loose, diarrhea), presence or absence of fecal blood (guaiac paper test and macroscopic evaluation of the anus), and weight loss. On day 6, intravital microscopy was performed and the mice were sacrificed. Colons were removed, from the cecum to the pelvic floor. Colon length and weight were measured before dividing the colon for histology and evaluation of MPO activity.

DSS load calculation. Previously, we demonstrated that in DSSinduced colitis, the severity of inflammation is DSS load-dependent, and that a critical DSS load greater than or equal to $30 \mathrm{mg}$ DSS/g body wt is required to reliably induce colitis in the C57BL/6J strain (29). DSS load for all DSS-treated mice was calculated as: load = [total drinking volume $(\mathrm{ml}) \times$ DSS $(\mathrm{g})$ per $100 \mathrm{ml}] /$ initial body wt $(\mathrm{g})$. The drinking volume was recorded daily using calibrated water bottles.

Histology. For each animal, histological examination was performed on three samples of the distal colon; samples were fixed in $10 \%$ formalin before staining with $\mathrm{H} \& \mathrm{E}$. All histological quantitation was performed blinded using a scoring system previously described (30). The three independent parameters measured were severity of inflammation (0-3: none, slight, moderate, severe), extent of injury (0-3: none, mucosal, mucosal and submucosal, transmural), and crypt damage (0-4: none, basal 1/3 damaged, basal 2/3 damaged, only surface epithelium intact, entire crypt and epithelium lost). The score of each parameter was multiplied by a factor reflecting the percentage of tissue involvement $(\times 1$ : $0-25 \%, \times 2: 26-50 \%, \times 3: 51-75 \%, \times 4: 76-100 \%)$ and all numbers were summed. Maximum possible score was 40 .

For determination of lamina propria leukocytes, H\&E-stained $5-\mu \mathrm{m}$ sections were examined under high-power magnification $(\times 25)$. Neutrophils in the lamina propria were counted in five randomly selected high-power fields on each slide and the average per slide was determined.

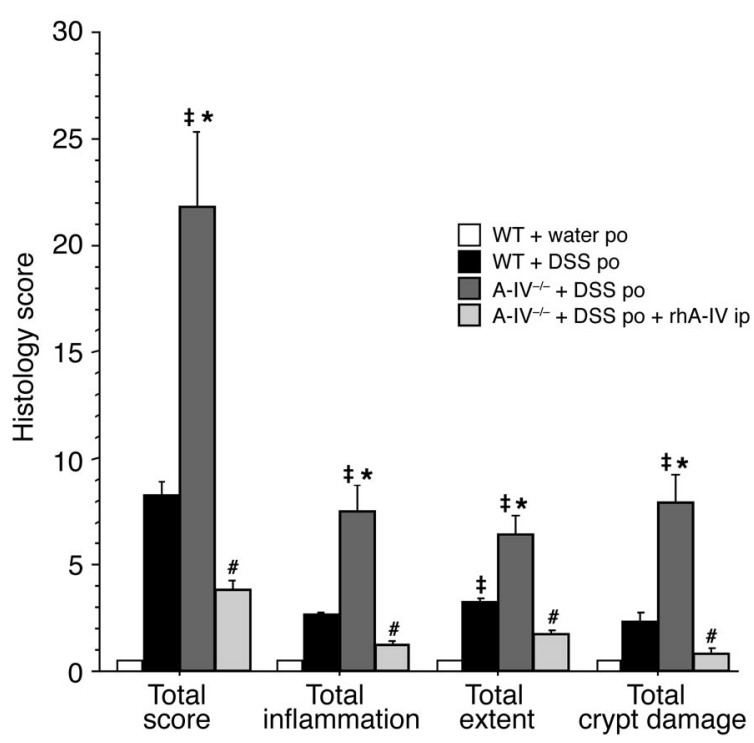

Figure 10

Histology score of colitis in WT mice treated with water (control) or DSS, and in ApoA-IV-l- mice treated with DSS alone or DSS + rhA-IV (mean $\pm \mathrm{SE}$ ). ${ }^{\ddagger} P<0.05 \mathrm{vs}$. WT mice treated with water, ${ }^{*} P<0.05 \mathrm{vs}$. WT mice treated with DSS, ${ }^{\#} P<0.05$ vs. ApoA-IV ${ }^{-1-}$ mice treated with DSS alone. 


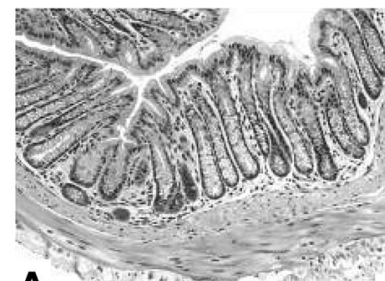

A
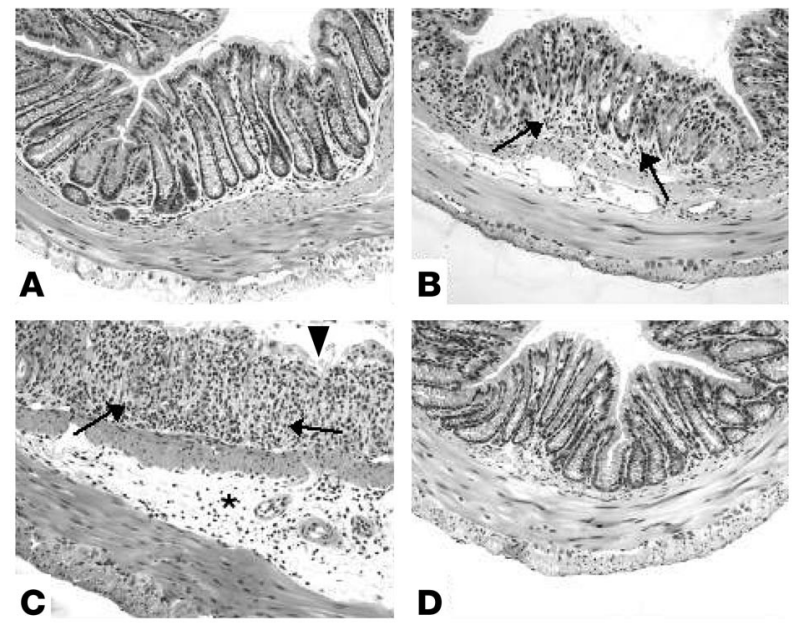

Figure 11

Histology (H\&E staining; magnification, $\times 100$ ) of colonic samples from WT mice receiving either water (control) or DSS, and from ApoA-IV-/animals receiving DSS or DSS + $0.5 \mathrm{mg}$ rhA-IV. Compared with WT control animals (A), colon of WT DSS-treated mice (B) showed only mild inflammation (arrows), whereas in $A p o A-I V^{-/-}$animals, DSS alone (C) produced loss of epithelial lining (arrowheads), edema (asterisk), and severe cellular inflammation (arrows). Treatment of DSS-treated ApoA- $/ V^{-/}$animals with $0.5 \mathrm{mg}$ rhA-IV prevented morphological damage and cellular infiltration (D).

Tissue MPO activity. MPO was measured in tissue from proximal to distal colon (adjacent to tissue used for histology). Samples were rinsed with cold PBS, blotted dry, and immediately frozen in liquid nitrogen. They were stored at $-80^{\circ} \mathrm{C}$ until assayed for MPO activity using the $o$-dianisidine method $(55,56)$. Tissue samples were thawed and weighed. The samples were then suspended (10\% wt/ vol) in $50 \mathrm{mM} \mathrm{pH} 6.0$ potassium phosphate buffer containing $0.5 \%$ hexadecyltrimethylammonium bromide $(0.1 \mathrm{~g} / 20 \mathrm{ml}$ potassium phosphate) and homogenized. A sample of the homogenate (1 $\mathrm{ml}$ ) was sonicated for 30 seconds, then centrifuged at $200 \mathrm{~g}$ for 10 minutes at $4^{\circ} \mathrm{C}$. The reaction was begun by mixing and incubating the supernatant $(100 \mu \mathrm{l})$ at $20^{\circ} \mathrm{C}$ for 10 minutes with a solution composed of $2,810 \mu \mathrm{l}$ of $50 \mathrm{mM}$ potassium phosphate, $30 \mu \mathrm{l}$ of $20 \mathrm{mg} / \mathrm{ml} o$-dianisidine dihydrochloride, and $30 \mu \mathrm{l}$ of $20 \mathrm{mM}$ hydrogen peroxide. After 10 minutes the reaction was terminated by the addition of $30 \mu \mathrm{l} 2 \%$ sodium azide. The change in absorbance was read at $460 \mathrm{~nm}$ in a spectrophotometer (UV-1201 Series; Shimadzu Scientific Instruments Inc., Kyoto, Japan). MPO activity was expressed as the amount of enzyme necessary to produce a change in absorbance of 1.0 unit per minute per g tissue (wet weight).

Blood sampling and platelet preparation. Platelets were derived from untreated C57BL/6J mice for all intravital experiments. Donor mice were anesthetized using ketamine hydrochloride $(150 \mathrm{mg} /$ $\mathrm{kg}$ intraperitoneally) and xylazine $(7.5 \mathrm{mg} / \mathrm{kg}$ intraperitoneally). As described previously (57), approximately $0.9 \mathrm{ml}$ of blood was harvested via a catheter placed in the carotid artery. The blood was collected in polypropylene tubes containing $0.1 \mathrm{ml}$ acid-citratedextrose buffer (Sigma-Aldrich, St. Louis, Missouri, USA). Plateletrich plasma was obtained by two sequential centrifugations (120 $g$ for 8 minutes and $120 \mathrm{~g}$ for 3 minutes). The platelet-rich plasma was removed and centrifuged again at $550 \mathrm{~g}$ for 10 minutes, and the pellet was resuspended in PBS, pH 7.4. Platelets were then incu- bated for 10 minutes at room temperature with the fluorochrome CFSE (90 M final concentration; Molecular Probes Inc., Eugene, Oregon, USA). The fluorescently labeled platelet solution was then centrifuged and the pellet was resuspended in $500 \mu \mathrm{l}$ of PBS and protected from light until infused into a recipient animal. Leukocytes accounted for $0.01 \%$ of the cells in the platelet suspension. The number of fluorescently labeled platelets obtained from one donor mouse was sufficient for two recipient mice.

Surgical preparation for intravital microscopy. Animals were anesthetized as described above. The right carotid artery was cannulated for blood pressure measurements using a disposable pressure transducer (Cobe Laboratories Inc., Lakewood, Colorado, USA) attached to a pressure monitor (BP-1; World Precision Instruments, Sarasota, Florida, USA). The right jugular vein was cannulated for infusion of rhodamine 6G (Sigma-Aldrich) for leukocyte labeling and subsequent infusion of CFSE-labeled platelets. On an adjustable acrylic microscope stage, a laparotomy was performed and the animal was placed on its right side. The proximal large bowel (initial $2-3 \mathrm{~cm}$ adjacent to the cecum) was exteriorized with moist cotton swabs, covered with a nonwoven sponge, and superfused at $37^{\circ} \mathrm{C}$ with bicarbonate-buffered saline solution ( $\mathrm{pH}$ 7.4).

Intravital fluorescence microscopy. Platelets and leukocytes were visualized with an inverted Nikon microscope (Nikon Inc., Tokyo, Japan) equipped with a 75-watt XBO xenon lamp. Visualization of CFSE (excitation: $490 \mathrm{~nm}$, emission: $518 \mathrm{~nm}$ ) and rhodamine $6 \mathrm{G}$ (excitation: $525 \mathrm{~nm}$, emission $550 \mathrm{~nm}$ ) required a Nikon filter block with an excitation filter (470-490 nm), a dichroic mirror $(510 \mathrm{~nm})$, and a barrier filter $(520 \mathrm{~nm})$. With a $\times 40$ objective (0.85 numerical aperture, Nikon Inc.), the magnification on the television screen (Trinitron PVM-2030, $50.6 \mathrm{~cm}$ diagonal; Sony Corp., Tokyo, Japan) was $\times 1,280$. The microscopic images were received by a charge-coupled device (CCD) video camera (model C2400; Hamamatsu Photonics KK, Hamamatsu, Shizuoka, Japan) and optimized by a CCD camera controller (model C2400; Hamamatsu Photonics KK). The images were recorded on a videocassette

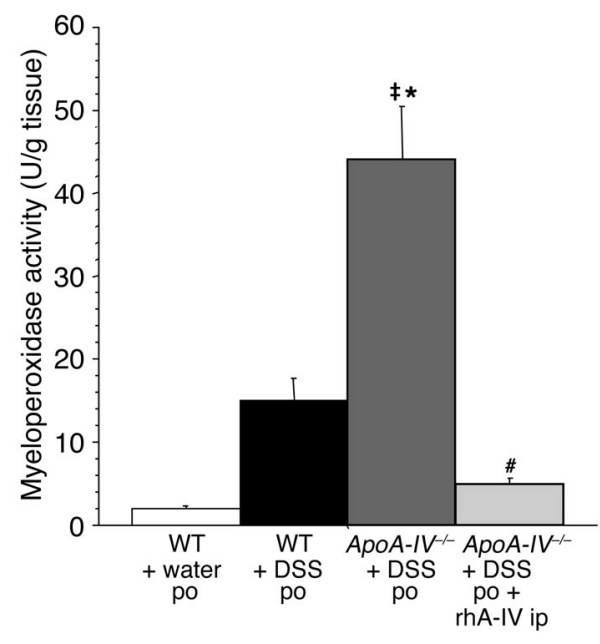

\section{Figure 12}

MPO activity in colonic tissue of WT mice treated with water (control) or DSS and in ApoA-IV--- mice treated with DSS alone or DSS + 0.5 $\mathrm{mg}$ rhA-IV, after 7 days (mean $\pm \mathrm{SE}$ ). $\neq P<0.05$ vs. WT treated with water, ${ }^{*} P<0.05$ vs. WT treated with DSS, ${ }^{\#} P<0.05$ vs. ApoA-IV-ltreated with DSS alone. 
recorder (HS-U65; Mitsubishi Digital Electronics America, Irvine, California, USA). A video time-date generator (Panasonic WJ810; Matsushita Electric Industrial Co., Osaka, Japan) projected the time, date, and stopwatch function onto the monitor. Five randomly chosen postcapillary venules of the proximal large bowel were each recorded for 1 minute.

Video analysis. Venular diameter (between $20 \mu \mathrm{m}$ and $40 \mu \mathrm{m}$ ) was measured with a video caliper (Microcirculation Research Institute, Texas A\&M University, College Station, Texas, USA) and venular length was set at $100 \mu \mathrm{m}$. Platelets and leukocytes were classified according to their interaction with the venular wall as either free flowing or adherent (when cells remained stationary for 30 seconds or more). We determined whether a platelet or leukocyte was adherent directly to the endothelium itself or indirectly by attachment to another blood cell, suggesting binding of blood cells to other blood cells and to endothelium. Platelet and leukocyte adherence was expressed as the number of cells per $\mathrm{mm}^{2}$ of venular surface, calculated from diameter and length, assuming cylindrical vessel shape.

Measurement of in vivo colonic P-selectin expression using dual radiolabeled $m A b$ technique. The binding $\mathrm{mAb}$ 's used for the in vivo characterization of P-selectin expression were RB40.34, a rat immunoglobulin $\left(\mathrm{IgG}_{1}\right)$ that is specific for mouse CD62P (P-selectin) (BD Biosciences - Pharmingen, San Diego, California, USA), and P23, a nonbinding murine $\operatorname{IgG}_{1}$ directed against human P-selectin (Pharmacia-Upjohn, Kalamazoo, Michigan, USA). The binding (RB40.34) and nonbinding (P23) mAb's were labeled with ${ }^{125} \mathrm{I}$ and ${ }^{131} \mathrm{I}$ (DuPont NEN Research Products, Boston, Massachusetts, USA), respectively, using the iodogen method as described previously (58), and stored at $4^{\circ} \mathrm{C}$. Mice were anesthetized as described above, then equipped with right jugular and carotid catheters. A mixture $(200-\mu \mathrm{l})$ of ${ }^{125}$ I-labeled binding mAb and ${ }^{131} \mathrm{I}$-labeled nonbinding $\mathrm{mAb}$ was administered through the jugular vein catheter. Five minutes after injection of the $\mathrm{mAb}$ mixture, a blood sample was obtained from the carotid artery. Immediately thereafter, the animal was rapidly exsanguinated by jugular perfusion of bicarbonate-buffered saline, immediately followed by carotid perfusion with bicarbonate-buffered saline after severing the inferior vena cava at the thoracic level. The large bowel was harvested and divided into proximal and distal portions. The method for calculating P-selectin expression has been described previously (58). Briefly, activity of ${ }^{125} \mathrm{I}$ and ${ }^{131} \mathrm{I}$ (marking the binding $\mathrm{mAb}$ and the nonbinding $\mathrm{mAb}$, respectively) in the tissue and in $50-\mu \mathrm{l}$ samples of cell-free plasma was counted in a 14800 Wizard $3 \gamma$ counter (Wallac, Turku, Finland). The accumulated activity of the labeled $\mathrm{mAb}$ in the colon was expressed as the percentage of the injected activity per $g$ tissue. P-selectin expression was calculated by subtracting the accumulated activity per $\mathrm{g}$ tissue of the nonbinding $\mathrm{mAb}$ from the activity of the binding $\mathrm{P}$-selectin-binding $\mathrm{mAb}$. This value, expressed as percent injected dose per g tissue, was converted to ng mAb per g tissue by multiplying the above value by the total injected binding $\mathrm{mAb}$.

Experimental protocols. In the first series of experiments, we tested different doses of intraperitoneally administered rhA-IV $(0.5 \mathrm{mg}$ and $0.25 \mathrm{mg}$ daily, $n=7 \mathrm{each}$ ) in DSS-induced colitis starting at day 0 for 7 days. Control C57BL/6J mice $(n=7)$ received water. Besides animals receiving DSS $(n=7)$, a vehicle control group received DSS + PBS intraperitoneally $(n=4)$. To control for nonspecific protein effects, two more DSS groups received BSA $(n=3)$ and $\operatorname{rhA}-\mathrm{I}(n=6)$ (both in molar dose equivalents to $0.5 \mathrm{mg} \mathrm{rhA}-\mathrm{IV} / \mathrm{d}$ ), respectively.

In the second series of experiments we examined the effect of rhA-IV on colonic microvasculature using intravital fluorescence microscopy. For 7 days, C57BL/6J mice received either water $(n=6)$, DSS $(n=6)$, or DSS + rhA-IV $(0.5 \mathrm{mg} / \mathrm{d})(n=6)$ until microscopy was performed. One hundred microliters of $0.02 \%$ rhodamine $6 \mathrm{G}$ was infused intrajugularly over 5 minutes and allowed to circulate for 5 minutes. Immediately thereafter, fluorescently labeled platelets $\left(100 \times 10^{6}\right)$ were infused over a period of 5 minutes using the infusion pump and then allowed to circulate for 5 minutes before beginning recording.

In a third series of experiments we tested whether apoA-IV deficiency aggravates DSS-induced colitis. All animals in this third series of experiments were kindly provided by the laboratory of Patrick Tso. The experimental groups were: WT C57BL/6J mice treated with water $(n=5)$; WT C57BL/6J mice (littermates of ApoA-IV $V^{-/-}$mice) treated with DSS $(n=6) ; A p o A-I V^{-/}$mice treated with DSS $(n=6)$; and $A p o A-I V^{-/}$mice treated with DSS + rhA-IV $(0.5 \mathrm{mg} / \mathrm{d}, n=6)$.

Data analysis. Statistical analyses were performed with StatView 4.5 software (Abacus Concepts Inc., Berkeley, California, USA) using one-way ANOVA followed by the Scheffé (post hoc) test. All values are reported as mean \pm SE. Statistical significance was set at $P<0.05$.

\section{Acknowledgments}

The authors are grateful to Fu Qin Duan, William Goodwill, and Heather Spaulding for technical assistance. We also thank Nicholas Duverger for generously providing us with the pL2102hA-IV plasmid. This study was supported by grants from the Deutsche Forschungsgemeinschaft, Bonn, Germany (VO 998/1-1 to T. Vowinkel), the NIH (P01 DK-43785 to D.N. Granger and R29 DK-52148 to T.J. Kalogeris), and by funds from the Department of Surgery at Louisiana State University Health Sciences Center.

Received for publication February 3, 2004, and accepted in revised form May 25, 2004.

Address correspondence to: Theodore J. Kalogeris, Department of Surgery, Louisiana State University Health Sciences Center, 1501 Kings Highway, Shreveport, Louisiana 71130-3932, USA. Phone: (318) 675-4354; Fax: (318) 675-6005; E-mail: tkalog@lsuhsc.edu.
1. Swaney, J.B., Braithewaite, F., and Eden, H.A. 1977. Characterization of the apolipoproteins of rat plasma lipoproteins. Biochemistry. 16:271-278.

2. Apfelbaum, T.F., Davidson, N.O., and Gickman, R.M. 1987. Apolipoprotein A-IV synthesis in rat intestine: regulation by dietary triglyceride. Am. J. Physiol. 252:G662-G666.

3. Hayashi, H., et al. 1990. Transport of lipid and apoliproteins A-I and A-IV in intestinal lymph of the rat. J. Lipid Res. 31:1613-1625.

4. Kalogeris, T.J., Fukagawa, K., and Tso, P. 1994 Synthesis and lymphatic transport of intestinal apolipoprotein A-IV in response to graded doses of triglyceride. J. Lipid Res. 35:1141-1151.

5. Ghiselli, G., Krishna, S., Beigle, Y., and Gotto, A.M. 1986. Plasma metabolism of apolipoprotein A-IV in humans. J. Lipid Res. 27:813-827.

6. Lefevre, M., and Roheim, P.S. 1984. Metabolism of apolipoprotein A-IV. J. Lipid Res. 25:1603-1610.

7. Goldberg, I.J., Scheraldi, C.A., Yacoub, L.K., Saxena, U., and Bisgaier, C.L. 1990. Lipoprotein C-II activation of lipoprotein lipase. Modulation by apolipoprotein A-IV. J. Biol. Chem. 265:4266-4272.

8. Bisgaier, C.L., et al. 1987. Effect of lecithin: cholesterol acyl transferase on distribution of apolipoprotein A-IV among lipoproteins of human plasma. J. Lipid Res. 28:693-703.

9. Fielding, C.J., Shore, V.G., and Fielding, P.E. 1972. A protein cofactor of lecithin: cholesterol acyltransferase. Biochem. Biophys. Res. Commun. 46:1493-1498.

10. Dvorin, E., Gorder, N.L., Benson, D.M., and Gotto, A.M. 1988. Apolipoprotein A-IV. A determinant for binding and uptake of high density lipoproteins by rat hepatocytes. J. Biol. Chem. 261:15714-15718.

11. Stein, O., Stein, Y., Lefevre, M., and Roheim, P. 1986. 
The role of apolipoprotein A-IV in reverse cholesterol transport studied with cultured cells and liposomes derived from an ether analog of phosphatidylcholine. Biochim. Biophys. Acta. 878:7-13.

12. Fujimoto, K., Cardelli, J.A., and Tso, P. 1992. Increased apolipoprotein A-IV in rat mesenteric lymph acts as a physiological signal for satiation. Am. J. Physiol. 262:G1002-G1008.

13. Fujimoto, K., Fukagawa, K., Sakata, T., and Tso, P. 1993. Suppression of food intake by apolipoprotein A-IV is mediated through the central nervous system in rats. J. Clin. Invest. 91:1830-1833.

14. Okumura, T., Fukagawa, K., Tso, P., Taylor, I.L., and Pappas, T.N. 1994. Intracisternal injection of apolipoprotein A-IV inhibits gastric secretion in pylorus-ligated rats. Gastroenterology. 107:1861-1864.

15. Duverger, N., et al. 1996. Protection against atherosclerosis in mice mediated by human apolipoprotein A-IV. Science. 273:966-968.

16. Cohen, R.D., et al. 1997. Reduced aortic lesions and elevated high density lipoprotein levels in transgenic mice overexpressing mouse apolipoprotein A-IV. J. Clin. Invest. 99:1906-1916.

17. Fournier, N., et al. 2000. Human apo A-IV overexpression in transgenic mice induces cAMP-stimulated cholesterol efflux from J774 macrophages to whole serum. Arterioscler. Thromb. Vasc. Biol. 20:1283-1292.

18. Ostos, M.A., et al. 2001. Antioxidative and antiatherosclerotic effects of human apolipoprotein A-IV in apolipoprotein E-deficient mice. Arterioscler. Thromb. Vasc. Biol. 21:1023-1028.

19. Qin, X., Swertfeger, D.K., Sheng, S., Hui, D.Y., and Tso, P. 1998. Apolipoprotein A-IV: a potent endogenous inhibitor of lipid oxidation. Am. J. Physiol. 274:H1836-H1840.

20. Ferretti, G., Baccheti, T., Bicchiega, V., and Curatola, G. 2002. Effect of human apo A-IV against lipid peroxidation of very low density lipoproteins. Chem. Phys. Lipids. 114:45-54.

21. Remaley, A.T., et al. 2001. Apolipoprotein specificity for lipid efflux by the human ABCA1 transporter. Biochem. Biophys. Res. Commun. 280:818-823.

22. Ross, R. 1993. The pathogenesis of atherosclerosis: a perspective for the 1990s. Nature. 362:801-809.

23. Cooper, D., Stokes, K.Y., Tailor, A., and Granger, D.N. 2002. Oxidative stress promotes blood cellendothelial cell interactions in the microcirculation. Cardiovasc. Toxicol. 2:165-180.

24. Elson, C.O., Sartor, R.B., Tennyson, G.S., and Riddel, R.H. 1995. Experimental models of inflammatory bowel disease. Gastroenterology. 109:1344-1367.

25. Cooper, H.S., Murthy, S.N.S., Shah, R.S., and Sedergran, D.J. 1993. Clinicopathologic study of dextran sulfate sodium experimental murine colitis. Lab. Invest. 69:238-249.

26. Okayasu, I., et al. 1990. A novel method in the induction of reliable experimental acute and chronic ulcerative colitis in mice. Gastroenterology. 98:694-702.
27. Krieglstein, C.F., et al. 2001. Regulation of murine intestinal inflammation by reactive metabolites of oxygen and nitrogen: divergent roles of superoxide and nitric oxide. J. Exp. Med. 9:1207-1218.

28. Krieglstein, C.F., et al. 2002. Collagen-binding $\alpha_{1} \beta_{1}$ regulates intestinal inflammation in experimental colitis. J. Clin. Invest. 110:1773-1782. doi:10.1172/ JCI200215256.

29. Vowinkel, T., Kalogeris, T.J., Mori, M., Krieglstein, C.F., and Granger, D.N. 2004. Impact of dextran sulfate sodium load on the severity of inflammation in experimental colitis. Dig. Dis. Sci. 49:556-564.

30. Dieleman, L.A., et al. 1998. Chronic experimental colitis induced by dextran sulphate sodium (DSS) is characterized by Th 1 and Th 2 cytokines. Clin. Exp. Immunol. 114:385-391.

31. Kruidenier, L., et al. 2003. Attenuated mild colonic inflammation and improved survival from severe DSS-colitis of transgenic $\mathrm{Cu} / \mathrm{Zn}-\mathrm{SOD}$ mice. Free Radic. Biol. Med. 34:753-765.

32. Gironella, M., et al. 2002. The role of P-selectin in experimental colitis as determined by antibody blockade and genetically deficient mice. J. Leukoc. Biol. 72:56-64.

33. Ganesan, R., and Summers, C. 1989. Glucocorticoids potentiate the dipsogenic action of angiotensin II. Brain Res. 499:121-130.

34. Perez Guaita, M.F., and Chiaraviglio, E. 1980. Effect of prostaglandin E1 and its biosynthesis inhibitor indomethacin on drinking in the rat. Pharmacol. Biochem. Behav. 13:787-792.

35. Siegmund, B., Lehr, H.A., and Fantucci, G. 2002. Leptin: a pivotal mediator of intestinal inflammation in mice. Gastroenterology. 122:2011-2025.

36. Domek, M.J., et al. 1995. Anti-neutrophil serum attenuates dextran sulfate sodium-induced colonic damage in the rat. Scand. J. Gastroenterol. 30:1089-1094.

37. Springer, T.A. 1994. Traffic signals for lymphocyte recirculation and leukocyte emigration: the multistep paradigm. Cell. 76:301-314.

38. Panés, J., and Granger, D.N. 1998. Leukocyteendothelial cell interactions: molecular mechanisms and implications in gastrointestinal disease. Gastroenterology. 114:1066-1090.

39. Schuermann, G.M., et al. 1995. Increased expression of cell adhesion molecule P-selectin in active inflammatory bowel disease. Gut. 36:411-418.

40. Wan, X.W., et al. 2002. Leukocyte rolling is exclusively mediated by P-selectin in colonic venules. Br. J. Pharmacol. 135:1749-1756.

41. Collins, C.E., Rampton, D.S., Rogers, J., and Williams, N.S. 1997. Platelet aggregation and neutrophil sequestration in the mesenteric circulation in inflammatory bowel disease. Eur. J. Gastroenterol. Hepatol. 9:1213-1217.

42. Collins, C.E., and Rampton, D.S. 1995. Platelet dysfunction: a new dimension in inflammatory bowel disease. Gut. 36:5-8.

43. Collins, C.E., Cahill, M.R., Newland, A.C., and
Rampton, D.S. 1994. Platelets circulate in an activated state in inflammatory bowel disease. Gastroenterology. 106:840-845.

44. Talbot, R.W., Heppell, J., Dozois, R.R., and Beart, R.W., Jr. 1986. Vascular complications of inflammatory bowel disease. Mayo Clin. Proc. 61:140-145.

45. Danese, S., et al. 2003. Platelets trigger a CD40dependent inflammatory response in the microvasculature of inflammatory bowel disease. Gastroenterology. 124:1249-1264.

46. Nofer, J.R., et al. 2002. HDL and arteriosclerosis: beyond reverse cholesterol transport. Atherosclerosis. 161:1-16.

47. Burger, D., and Dayer, J.M. 2002. High-density lipoprotein-associated apolipoprotein A-I: the missing link between infection and chronic inflammation. Autoimmun. Rev. 1:111-117.

48. Cockerill, G.W., et al. 2001. Elevation of plasma high-density lipoprotein concentration reduces interleukin-1-induced expression of E-selectin in an in vivo model of acute inflammation. Circulation. 103:108-112.

49. Saijo, F., et al. 2003. Apolipoprotein A-IV protects vascular endothelial cells from oxidant-induced barrier dysfunction [abstract]. FASEB J. 17:A885.

50. Spaulding, H.L., Aw, T.Y., and Kalogeris, T.J. 2004. Apolipoprotein A-IV prevents oxidant-induced, redox-dependent apoptosis [abstract]. FASEB J. 18:A1030.

51. Weinstock, P.H., et al. 1997. Decreased HDL cholesterol levels but normal absorption, growth and feeding behavior in apolipoprotein A-IV knockout mice. J. Lipid Res. 38:1782-1794.

52. Duverger, N., et al. 1991. Functional characterization of human recombinant apolipoprotein A-IV produced in Escherichia coli. Eur. J. Biochem. 201:373-383.

53. Panagotopulos, S.E., Witting, S.R., Horace, E.M., Maiorano, N.J., and Davidson, W.S. 2002. Bacterial expression and characterization of mature apolipoprotein A-I. Protein Expr. Purif. 25:353-361.

54. Ebaugh, F.G. 1959. Quantitative measurement of gastrointestinal blood loss. J. Lab. Clin. Med. 53:777-788.

55. Arndt, H., Kubes, P., Grisham, M.B., Gonzalez, E., and Granger, D.N. 1992. Granulocyte turnover in the feline intestine. Inflammation. 16:549-559.

56. Krawisz, J.E., Sharon, P., and Stenson, W.F. 1984. Quantitative assay for acute intestinal inflammation based on myeloperoxidase activity. Assessment of inflammation in rat and hamster models. Gastroenterology. 87:1344-1350.

57. Cooper, D., Chitman, K.D., Williams, M.C., and Granger, D.N. 2003. Time-dependent platelet-vessel wall interactions induced by intestinal ischemiareperfusion. Am. J. Physiol. Gastrointest. Liver Physiol. 284:G1027-G1033.

58. Eppiheimer, M.J., Wolitzky, B., Anderson, D.C, Labow, M.A., and Granger, D.N. 1996. Heterogeneity of E- and P-selectins in vivo. Circ. Res. 79:560-569. 